\title{
A CONCEPT FOR PHYSIOLOGICAL USER DESCRIPTION IN THE CONTEXT OF DUAL USER INTEGRATION
}

\author{
Schröppel, Tina; Diepold, Theresia; Miehling, Jörg; Wartzack, Sandro \\ Friedrich-Alexander-Universität Erlangen-Nürnberg
}

\begin{abstract}
In order to ensure the user's acceptance towards a product, the user has to be captured with all his facets and requirements. In this context, many user-centred design methods only focus on single aspects such as subjective expectation or ergonomic product design. Correlations and connections or a common consideration of several user parameters are often neglected, even if this can provide useful information for improving the design of products. Dual user integration tries to close this gap to a certain extent and considers the user's subjective expectation in combination with their physiological capacities. An integral part of this approach is a target-oriented evaluation of the user. Currently available methods of physiological and subjective evaluation of the user are only partially applicable for dual user integration. Especially physiological measurement techniques are time-consuming and expensive. For this reason, this contribution presents a new concept for capturing and describing the physiological capacity of the user via semantic differentials. Thereby, motor functions, cognition and perception are considered.
\end{abstract}

Keywords: User centred design, Design methods, Integrated product development, Dual user integration, Physiological user description

\section{Contact:}

Schröppel, Tina

Friedrich-Alexander-Universität Erlangen-Nürnberg

Engineering Design

Germany

schroeppel@mfk.fau.de

Cite this article: Schröppel, T., Diepold, T., Miehling, J., Wartzack, S. (2019) 'A Concept for Physiological User Description in the Context of Dual User Integration', in Proceedings of the 22nd International Conference on Engineering Design (ICED19), Delft, The Netherlands, 5-8 August 2019. DOI:10.1017/dsi.2019.386 


\section{MOTIVATION}

Efficient functionality as well as good usability and a high level of user acceptance often forms the basis for successful products. In this context, especially subjective and physiological user needs are of rising importance. Because after all, it is an emotional process whether to like a product or not (Kotler and Armstrong, 2016), whereas an ergonomic product design, on the other hand, provides the basis for good usability (Bubb et al., 2016). Hereby, subjective and physiological aspects have to be considered as equally important to avoid negative effects on product usage and acceptance. Good-looking products that cannot be properly utilized, for example, are just as unlikely to be used as those having a high usability but do not fit the user's subjective expectation. Considering both aspects together, this enables a subjectively user-oriented and physically suitable product design. To achieve this purpose, a method to systematically support the integration of subjective and physiological user needs in product development processes is currently under development - it is called dual user integration.

The basis for this method is an adequate user description providing insights about the subjective expectation as well as the physical capacity of the user. Schröppel and Wartzack (2018) already identified and analysed existing methods in terms of their potential for this dual kind of user description. Especially approaches describing the physical capacity of the users are often timeconsuming, expensive and/or location-based and therefore are not ideal in terms of dual user integration. Therefore, this contribution focuses especially on the physiological part of dual user integration and presents a new model for the fast and easy physiological user description.

\section{CURRENT STATE OF PHYSIOLOGICAL AND SUBJECTIVE USER DESCRIPTION}

The primary aim of dual user integration is the development and optimization of products in terms of physiological and subjective user demands. In particular, persons suffering from physical impairments, which still have a high subjective desire, can benefit from this approach. Before necessary analyses and useful conclusions can be derived, the physiological capacity of a user as well as his subjective expectations towards a product need to be identified and captured quantitatively. Within this context of user description, a large number of determinants can be detected (Figure 1). Especially subjective user needs underlie various influencing factors like emotions, the personality of the user, their personal values and attitudes, the current motivation or well-being (Desmet and Pohlmeyer, 2013; Zöller and Wartzack, 2017). Physiological user needs on the other hand can be reduced to four main topics: motor, cognitive and sensory capabilities as well as anthropometric characteristics (Wickens et al., 2004).
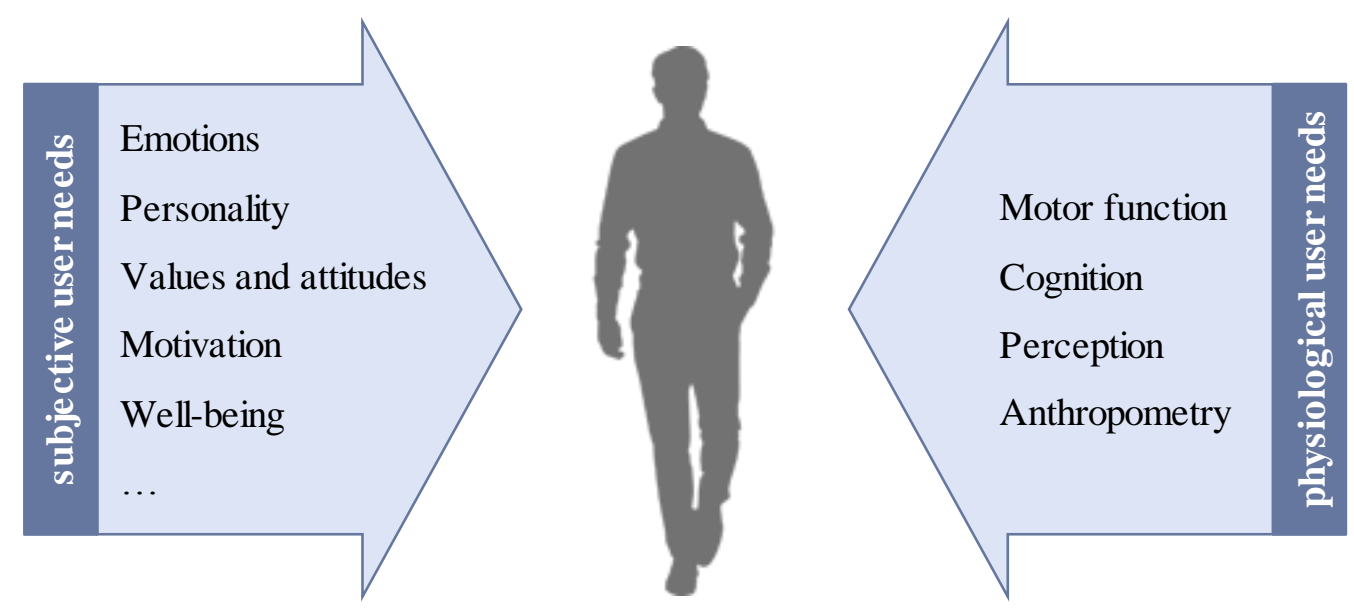

Figure 1. Possible relevant subjective and physiological user needs; own representation after (Desmet and Pohlmeyer, 2013; Zöller and Wartzack, 2017; Wickens et al., 2004)

To actually capture the user's needs, there are different methods and models that can be applied. Thinking about subjective user needs, Russell (1980), for instance, introduced a circumplex model of affect with which experienced emotions can be classified in relation to the dimensions of valence and arousal. A common way to capture the personality is the five factor model. Hereby, a person can be 
described in terms of five different personality traits: openness, conscientious, extraversion, agreeableness and neuroticism (Goldberg, 1990). Attitudes can be measured directly via questionnaires or self-information sheets that include rating scales like Likert scales or semantic differentials for instance (Robins et al., 2016). Semantic differentials are opposing word pairs that quantitatively measure whether the participant is more or less attached to one of the mentioned words (Osgood, 1957). Figure 2 shows an example of a semantic differential. There are also indirect measurement techniques like affective priming or the implicit association test. Both methods use reaction times to determine the individual attitudes of the participants (Wentura and Degner, 2006). One possible way to measure motivation is the so called motivation assessment system. It is a basic survey to evaluate the motivation of employees and based on the Pritchard-Ashwood theory of motivation (Schmerling, 2013). The intergovernmental economic organisation OECD (Organisation for Economic Co-operation and Development) published a guideline for measuring subjective wellbeing helping researcher to create suitable questionnaires (OECD, 2013).

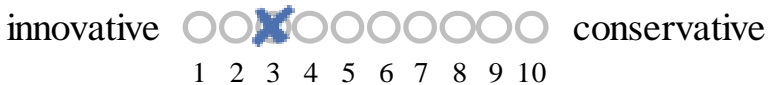

Figure 2. Example of a semantic differential

Beside subjective approaches, there are also different methods and techniques to capture physiological user needs. Motor functions can be divided into endurance, strength, speed, coordination and mobility. To measure them either single methods like using a force-measuring frame (Wakula et al., 2009) or overall approaches like a questionnaire to generally record the status of motoric functions by Bös et al. (2002) can be applied. Cognitive abilities can be evaluated with the so called "mini-mental state"exam where the participant has to write sentences, copy polygons, follow commands and vocally respond to questions that cover orientation, memory and attention (Folstein et al., 1975). Regarding the sensory system, visual tests like the contrast sensitivity test or the visual field test can provide information about the visual abilities of a person (cf. Wall and Sadun, 1989). Anthropometric data and how to collect them is primarily found in standards and guidelines (e.g. DIN, 2008, 2017). The measuring of the user is often realized manually using instruments like an anthropometer or a spreading caliper, but also automatically by 3D body scanners (Hotzman et al., 2011).

\section{NEED FOR ACTION}

In terms of capturing the subjective expectations of the user, there are already existing quantitative methods like semantic differentials that are quick and easy to handle and thus can be adapted for subjective user description (see section 2). From a physiological perspective, many of those presented methods are time-consuming and expensive or require a certain amount of expert knowledge. Thus, they are less suitable for the description of physiological user needs in the context of dual user integration (Schröppel and Wartzack, 2018). Hence, the aim of this contribution is the development of a new model for identifying the physical capacity of the user. Hereby, the interplay between the subjective and physiological user description needs to be considered. Accordingly, the general structure of dual user description is presented in section 4.1 before the actual concept for capturing the physical capacity of a user is introduced in section 4.2.

\section{INTRODUCING A CONCEPT FOR PHYSIOLOGICAL USER DESCRIPTION IN THE CONTEXT OF DUAL USER INTEGRATION}

In the following sections, the general structure of dual user description is presented (section 4.1) as well as the main concept of capturing the physical capacity of the user (section 4.2). Sections 4.2.1 to 4.2.3 give detailed descriptions of the different subareas of physiology that are part of the concept.

\subsection{General structure of dual user description}

Dual user integration aims to support product developers during the systematic optimization of products considering subjective and physiological user needs (Schröppel et al., 2019). This approach first needs a basic user description containing both perspectives to provide transparency regarding the subjective expectation as well as to evaluate the physical capacity of the user to reveal existing 
limitations of a person. The strength of the targeted methodology of dual user integration is the ability to consider both perspectives simultaneously rather than consecutively. To ensure this, the applied methods inside the methodology have to be highly comparable - especially the basic database, i.e. the collected subjective and physiological user data. In addition to good comparability, the information given to the product developer needs to have the right format. According to Goodman et al. (2007) information in the context of user-centred design should be concise, visual, flexible and intuitive as well as quick and easy to use.

For assessing the user's subjective needs, a focus on the user's attitudes is an appropriate way (Zöller and Wartzack, 2017). To properly describe and collect the user's attitudes semantic differentials will be used. It's an easy to handle and robust quantitative measurement technique that fits the required format by Goodman et al. (2007). Hereby, selected opposing impression pairs like exclusive/common or innovative/conservative are chosen to represent the user's attitude (Kett and Wartzack, 2016) (see Figure 3 left). Frey (1993) defined 30 of those word pairs providing a general view on the user's attitude. To ensure the previously mentioned comparability, the physiological user description should have a similar structure (see Figure 3 right). For this purpose, the physiological description of the user is also expressed by semantic differentials. This results in a physiological capacity profile of the user from which impairments and limitations can be derived.

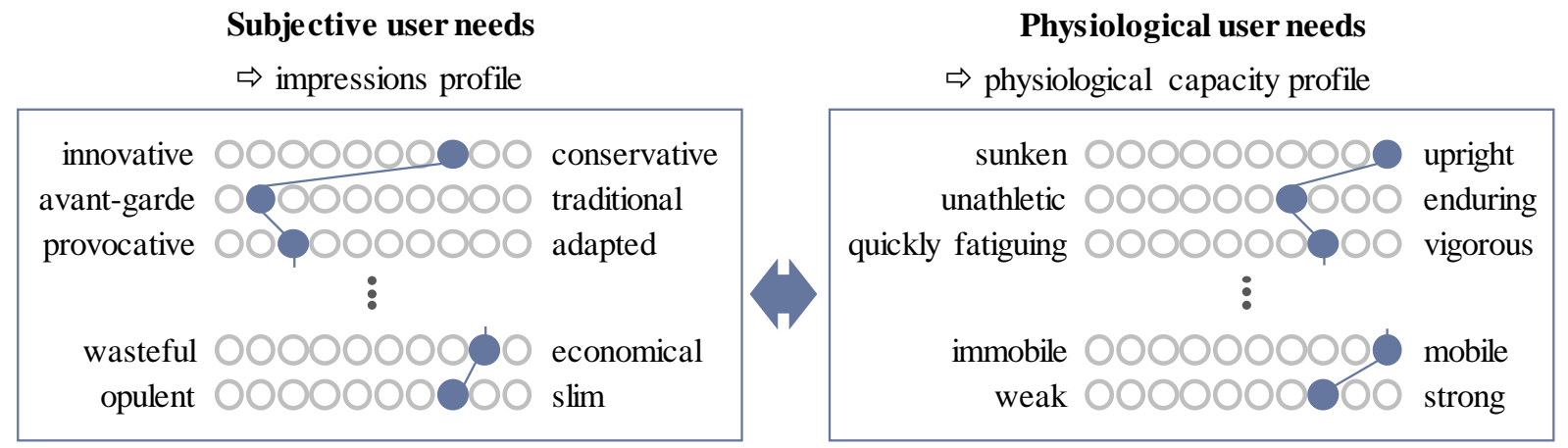

Figure 3. General structure of dual user description (with exemplary profiles)

Using the same measuring technique offers several advantages. On the one hand, the product developer only has to learn one method, which is additionally easy to understand due to the presented format of the information. On the other hand, the same data structure is created for subjective and physiological perspective. Thus, subsequently conducted optimizations or general analyses of the data can be carried out more quickly and more efficiently. Summarized, the use of semantic differentials allows a fast and for the user understandable acquisition of personal capabilities and attitudes, which can be easily compared due to the same data structure.

\subsection{Concept to measure physiological user capacity}

The aim of the model for measuring the physical capacity of a user is the identification of physiological limitations. Those can then be efficiently considered in product design by the product developer. Four main areas can be identified for a broad physiological description of the user in the context of product development. These are motor and cognitive abilities as well as sensory perception and anthropometric characteristics (Wickens et al., 2004). However, especially in anthropometry there are numerous national and international databases containing user parameters with different ethnical background, age or gender. In today's product development such data often serves as the fundament for digital human models which can be used to virtually validate and optimize products in terms of ergonomic suitability (Miehling et al., 2015). Therefore, this aspect of physiology is initially excluded from the concept of measuring physiological capacity. The remaining aspects (motor, cognitive and sensory abilities) will be considered and transferred into the concept to measure physiological user capacity. As already mentioned in section 4.1, semantic differentials shall be used in this context. The derivation of them requires a more detailed differentiation of motor function, perception and cognition, which is shown in Figure 4. 


\begin{tabular}{|c|c|c|}
\hline \multirow{5}{*}{ 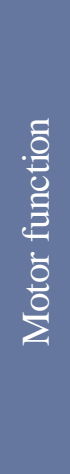 } & endurance & general endurance, special endurance \\
\hline & strength & $\begin{array}{l}\text { driving force, braking force, manipulation force, operating force, } \\
\text { action forces on body support surfaces, posture, retention force }\end{array}$ \\
\hline & speed & responsiveness, action speed \\
\hline & coordination & $\begin{array}{l}\text { coupling ability, flexibility, kinaesthetic differentiability, spatial } \\
\text { orientation, ability to balance, ability to respond, ability to rythm }\end{array}$ \\
\hline & mobility & $\begin{array}{l}\text { static mobility, dynamic mobility, active mobility, } \\
\text { passive mobility }\end{array}$ \\
\hline
\end{tabular}

\begin{tabular}{|c|c|c|}
\hline \multirow{3}{*}{ 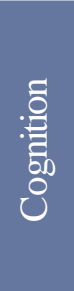 } & attention & $\begin{array}{l}\text { alertness, vigilance, permanent attentiveness, cognitive } \\
\text { processing speed, selective and divided attention }\end{array}$ \\
\hline & memory & $\begin{array}{l}\text { long-term memory, working memory, remote memory, } \\
\text { prospective memory, explicite and implicite memory, }\end{array}$ \\
\hline & $\begin{array}{l}\text { executive } \\
\text { functions }\end{array}$ & $\begin{array}{c}\text { drive, planning, problem solving, initiation and inhibition of } \\
\text { action, control of action }\end{array}$ \\
\hline
\end{tabular}

\begin{tabular}{|c|c|}
\hline vision & identifying disabilities concerning vision \\
\hline hearing & identifying disabilities concerning hearing \\
\hline taste & identifying disabilities concerning taste \\
\hline smell & identifying disabilities concerning smell \\
\hline
\end{tabular}

Figure 4. Differentiation of motor, cognitive and sensory abilities as basis for derivation of semantic differentials; based on (Bös and Mechling, 1983; Güllich and Krüger, 2013; Schlick et al., 2010; Meinel and Schnabel, 2018; Götze et al., 2005)

The selected structure enables the development of semantic differentials as it clearly illustrates the meaning of those multifaceted physiological components. For example, coordination as part of motor functions is divided into seven individual elements like the ability of spatial orientation and balance. For each component, opposing word pairs can be derived that describe them and their connected elements as best as possible (see sections 4.2.1 to 4.2.3). To prevent linguistic misunderstandings and therefore the falsification of the results, special attention was given to uniqueness, clarity and easy understanding of the semantic differentials. Their structure is kept similar: the word on the right side describes the normal performance of a healthy person, the opposing word indicates physical disabilities. Figure 5 shows the example of 'unathletic - enduring'. Hereby, a healthy and normally trained participant would select one of the right expressions. Physical impaired persons would select an option further to the left.

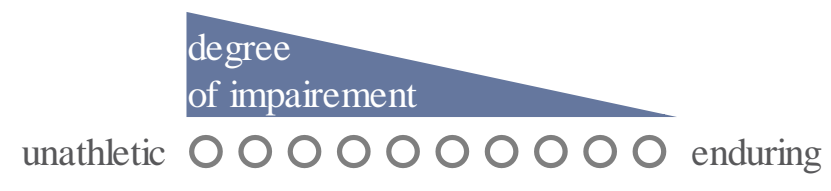

Figure 5. Standard set-up of semantic differentials in the context of physiological capacity profiling (example of unathletic - enduring) 
It is assumed, that a person with normal physiological abilities will choose the highest possible expression towards the side of the semantic differential indicating health (right word). Therefore, within this concept, higher-than-average capacities cannot be recorded. However, designing products for people with average capacities normally includes the high performer. More important is the identification of disabilities which may require a design optimization of the product by the developer.

\subsubsection{Measuring motor function}

For measuring motor functions a two-step classification is made. The main components are endurance, strength, speed, coordination and mobility (Bös and Mechling, 1983). To find suitable semantic differentials a further division into specific elements is needed. According to Güllich and Krüger (2013), endurance is defined as general and special endurance. General endurance refers to stress affecting the cardiovascular system, i.e. stress on the entire body or large muscle groups. Thus, a general term is chosen as semantic differential: 'breathless - enduring'. Special endurance in contrast is application-related and usually correlates with the strength in the context of user-product interaction. Therefore, 'feeble - vigorous' is chosen as opposing word pairs.

Schlick et al. (2010) divide the physical strength of the user in forces occurring inside the body and action forces that carry the physical strength to the outside. With regard to product usage and thus relevant for product development action forces are considered including driving/ braking/ manipulation/ operating forces as well as action forces on body support surfaces, posture and retention forces. Postural strength refers to the ability to maintain a posture and is captured by the semantic differential 'sunken - upright'. The remaining elements are summarized by the word pair 'weak strong'. This unification is done because it is more intuitive for a person to answer how weak or strong he is in general instead of thinking about how well a certain interaction can be completed (e.g. holding or moving an object). So asking about the strength in general automatically allows a prediction on how well strength-intensive interactions can be performed. Still, the strength can vary within different parts of the body (e.g. arm or leg). Therefore and if necessary for product design, the selected semantic differential can be specified by including the affected body parts as well as the relevant side of the body (e.g. 'weak - strong (left arm)'). Consequently, depending on the number of affected body parts the number of semantic differentials will increase.

Speed is divided into two elements. Responsiveness refers to reacting to a stimulus as quickly as possible, whereas action speed describes the speed at which movements can be performed (Güllich and Krüger, 2013). Responsiveness is measured by the semantic differential 'slow - reactive' and the action speed by 'sluggish - quick'.

Following Meinel and Schnabel (2018) coordination includes coupling ability, flexibility, kinaesthetic differentiability, spatial orientation, ability to balance, ability to respond, ability to rhythm. The capability to couple describes the ability to coordinate or perform different movements simultaneously. Therefore, the chosen semantic differential is 'one task at a time - capable of multitasking'. Flexibility is the ability to handle changing situations, e.g. by modifying a current movement, and is consequently described by the word pair 'inflexible - flexible'. Kinaesthetic differentiability is about the degree of accuracy while performing motion. It is expressed by 'grossmotoric - fine-motoric'. The spatial orientation can be captured by the word pair 'disoriented oriented'. Balance is about keeping the body in the right position without falling. The appropriate semantic differential for this is 'shaky - balanced'.

The ability to respond strongly correlates with the already mentioned responsiveness and therefore, is already sufficiently captured by the existing semantic differential 'slow - reactive'. Lastly, the ability to rhythm is an indicator of whether rhythms can be detected and reproduced or not. It is represented by the word pair 'not rhythm-capable - rhythm-capable'.

The last component of motor functions is mobility which contains the static, dynamic, active and passive mobility (Meinel and Schnabel, 2018). Whereas static mobility is about maintaining certain joint positions for a short time, dynamic mobility involves energetic movements. In the context of the evaluation of physiological capacity profiles, it is not intended to consider each joint individually, but rather to derive a general idea of whether the user is capable of dynamic movements at all. Therefore, the two elements are generally described by two semantic differentials: 'limited static movement static movement' and 'limited dynamic movement - dynamic movement'. In contrast, active mobility is considered in a more differentiated manner. A restriction of movement often requires a design change to the product, which in turn depends on the location of the reduced mobility of the 
user. Thus, similar to the strength a general semantic differential ('immobile - mobile') is used for each relevant joint (thumb, finger, wrist, elbow, hip, knee, ankle) and side of the body (left, right). If necessary, the passive mobility can be detected equivalent to the active mobility. Only a reference to the passive character of the movability shall be included (e.g. 'passively immobile - passively movable (left elbow)'). Equally to strength, depending on the number of affected joints the number of semantic differentials will increase. To conclude, Figure 6 summarizes the basic items for physiological capacity profiling in terms of motor functions.

$\begin{aligned} & \text { breathless } 0000000000 \text { enduring } \\ & \text { feeble } 0000000000 \text { vigorous } \\ & \text { sunken } 0000000000 \text { upright } \\ & \text { weak } 0000000000 \text { strong (optional: left/right + body part) } \\ & \text { slow } 000000000 \text { reactive } \\ & \text { sluggish } 0000000000 \text { quick } \\ & \text { inflexible } 0000000000 \text { flexible } \\ & \text { gross-motoric } 0000000000 \text { fine-motoric } \\ & \text { disoriented } 0000000000 \text { oriented } \\ & \text { shaky } 0000000000 \text { balanced } \\ & \text { not rythm-capable } 0000000000 \text { rythm-capable } \\ & \text { limited static movement } 0000000000 \text { static movement } \\ & \text { limited dynamic movement } 0000000000 \text { dynamic movement } \\ & \text { immovable } 0000000000 \text { mobile (optional: left/right + joint) } \\ & \text { passively immovable } 0000000000 \text { passively movable (optional: left/right }+ \text { joint) }\end{aligned}$

Figure 6. Physiological capacity profile for motor functions

\subsubsection{Measuring cognition}

Cognition also consists of different components. Götze et al. (2005) distinguish between attention, memory and executive functions. This classification seems appropriate in the context of product development because it suitably describes the interaction between product and user. One element of attention is called alertness and describes the general arousal of people. As semantic differential 'distracted - attentive' is chosen. Besides, vigilance and permanent attentiveness is about the ability to stay focused on a specific situation in the long-term or under monotonous conditions. Those two elements are captured by the word pair 'unable to concentrate - long-term concentration'. Cognitive processing speed refers to how slowly or quickly changes (e.g. of a situation) can be detected by a person. Accordingly, the corresponding semantic differential is 'slow thinking - quick thinking'. The ability to concentrate on one single stimulus or different stimuli at the same time is split into selective and divided attention and captured as 'distracted - divided attention'.

The second component of cognition is memory which includes long-term, working, remote, prospective as well as explicit and implicit memory (Götze et al., 2005). The long-term memory stores content for years, whereas the working memory only holds short-term information. Remote memory, on the other hand, refers to events that occurred a long time ago, such as childhood memories for adults. All three mentioned memories refer to the temporal aspect of information storage. In this context working memory is captured by 'lack of short-term memory - good short-term memory'. Long-term and remote memory both addresses the long-term perspective and therefore reduced to only one word pair 'lack of long-term memory - good long-term memory'. A further division of working memory refers to the specific way in which knowledge is stored. This means that either words and numbers or spatial and pictorial aspects are more likely to be retained. Since this is of great importance for product development, for example in the design of interfaces, the word pairs 'bad linguistic information processing - good linguistic information processing' as well as 'bad visual information processing - good visual information processing' are added additionally. The prospective memory summarizes all cognitive abilities required to plan specific activities in advance and to retrieve and execute them on another occasion (Kliegel and Jäger, 2006). Thus, 'oblivious organised' is a suitable semantic differential. Götze et al. (2005) categorize memory into explicit and 
implicit which gives information about the way knowledge is absorbed by the user. This process can be consciously or unconsciously. Because it is assumed that human beings cannot give a valid statement about unconsciously perceived information this aspect is excluded for the concept of physiological user description.

The last of the three mentioned components of cognition are executive functions. These are divided into drive, planning, problem solving, initiation and inhibition of actions as well as the control of actions. Drive is all about the inner motivation of a person and can be described as 'listless energetic'. Planning includes the ability of a person to take any problems that may arise into account before they occur. The resulting semantic differential is 'aimless - long-sighted'. To solve problems, the general ability to properly assess situations is required as well as the courage to stop actions that have no perspective of success and instead find new solutions. It is summarized by the word-pair 'not solution-oriented - solution-oriented'. The initiation or inhibition of actions can easily be described with 'lack of initiative - proactive'. Action control is the last mentioned executive function and describes the repetitive monitoring of a person's action (e.g. checking temperature while heating a furnace). This results in the word pair 'lack of control - supervising'. Figure 7 gives an overview of the basic semantic differentials corresponding to the evaluation of cognition for physiological capacity profiling.

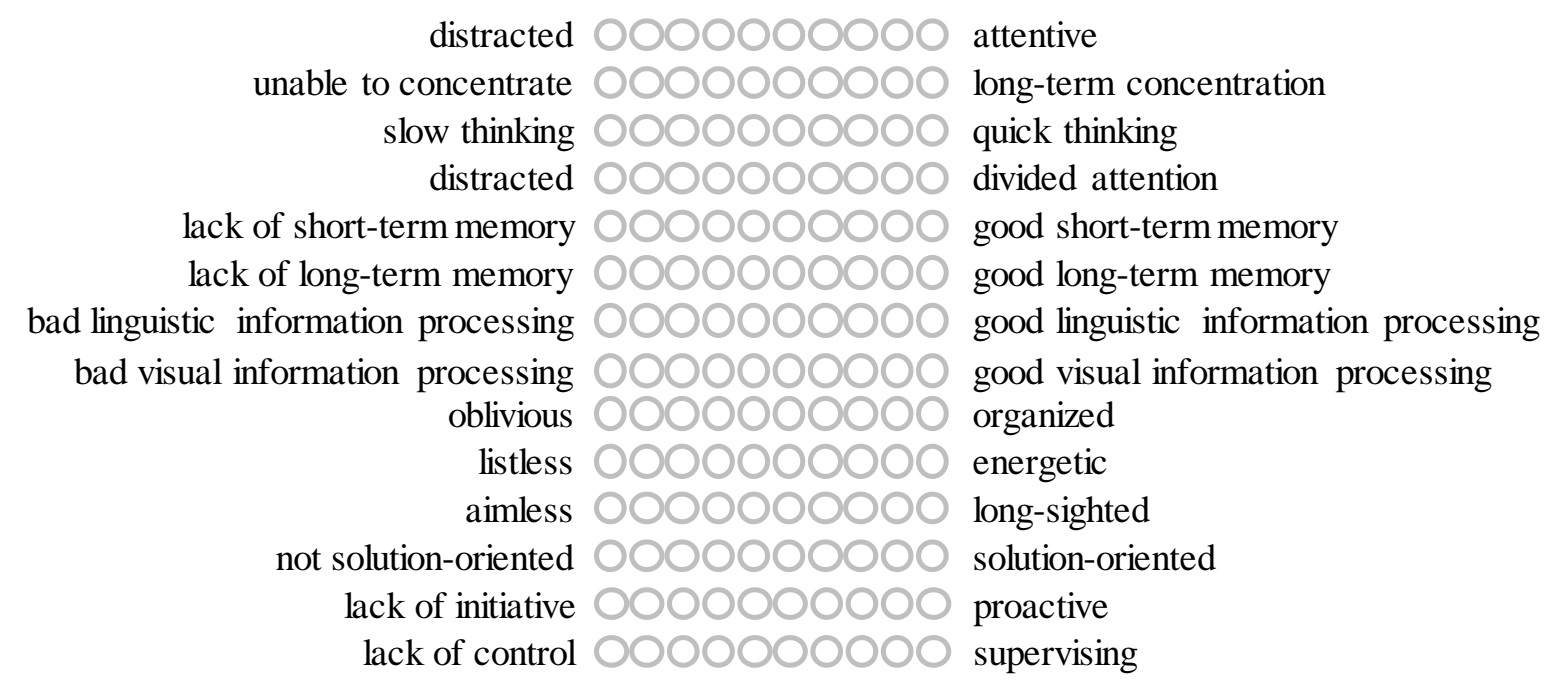

Figure 7. Physiological capacity profile for cognition

\subsubsection{Measuring perception}

To develop the capacity profile for measuring perception the so-called QOSI-matrix (Quantified Object Sensation Input) introduced by Balters et al. (2015) can be used to identify relevant aspects of a product that a user can detect with the five senses vision, hearing, taste, smell and touch. In terms of vision for example light intensity, colour, motion, depth and form are presented. However, many of those aspects are too specific to intuitively be evaluated by a participant. To overcome this challenge, attention will be focused on the few relevant components that are familiar to the user and can be answered intuitively. With regard to vision, it is of interest whether a visual impairment exists or not. This can be measured using the semantic differential 'blind - no visual disability'. Thus visual impairments of any kind are summarized. Hearing, taste and smell are evaluated equivalently with the following opposing word pairs: 'deaf - no hearing disability', 'loss of taste - normal sense of taste' and 'odour loss - normal sense of smell'. Regarding touch, the ability to sense vibrations, temperatures or pressure should be focused on. Those can be described together with the semantic differential 'loss of sensitivity - normal sense of touch'. In contrast to the other senses, sensitivity disorders can occur anywhere on the body. If necessary, the word pair can be provided with a reference to certain body parts. Figure 8 summarizes the basic items for physiological capacity profiling in terms of perception. 


\author{
blind 0000000000 no visual disability \\ deaf 0000000000 no hearing disability \\ loss of taste 0000000000 normal sense of taste \\ odour loss 0000000000 normal sense of smell \\ loss of sensitivity 0000000000 normal sense of touch \\ (optional: left/right + body part)
}

Figure 8. Physiological capacity profile for perception

\title{
5 CONCLUSION AND FUTURE RESEARCH
}

In order to successfully apply dual user integration, an efficient way to capture subjective user expectations and physiological user demands is needed. To enable an adequate physiological user description, this contribution presents a model for identifying the physical capacity of the user. The use of semantic differentials including motor, cognitive and sensory abilities results in physiological capacity profiles with a total of 35 opposing word pairs (see Figure 6 - Figure 8). In terms of the motor abilities strength and mobility as well as the sensory system touch, the presented basic profiles may be extended in relation to affected parts, joints and sides of the body (see section 4.2.1 and 4.2.3). In the end, the product developer can extend or reduce those profiles to provide a clear and efficient physiological database for the intended application.

However, there is still future research to do. First of all, the evaluation of the concept is pending. The understanding of the wording as well as the reliability of the profiles need to be validated. Furthermore, an extension of the concept in terms of anthropometry should be considered. To improve and furtherly objectify the interpretation of the results, appropriate standards should be attached to the scaling of the semantic differentials. To enable dual product optimization, the comparability to the subjective description of the user and the transfer of the results into product development must be further investigated.

\section{REFERENCES}

Balters, S., Bisballe Jensen, M. and Steinert, M. (2015), "Physiological and Sensorial Based Quantification of Human-Object-Interaction-the QOSI Matrix", In: C. Weber, S. Husung, G. Cascini, M. Cantamessa, D. Marjanović and M. Bordegoni, (Ed.), Proceedings of the 20th International Conference on on Engineering Design (ICED15) Vol 11: Human Behaviour in Design, Design Education, Milan, 27.-30.07.2015, Design Society, Glasgow, pp. 121-132.

Bös, K., Abel, T., Woll, A., Niemann, S., Tittlbach, S. and Schott, N. (2002), "Der Fragebogen zur Erfassung des motorischen Funktionsstatus (FFB-Mot)", Diagnostica, Vol. 48 No. 2, pp. 101-111.

Bös, K. and Mechling, H. (1983), Dimensionen sportmotorischer Leistungen, Hofmann, Schorndorf.

Bubb, H., Popova-Dlugosch, S. and Breuninger, J. (2016), "Ergonomische Produktgestaltung", In: U. Lindemann, (Ed.), Handbuch Produktentwicklung, Carl Hanser Verlag, München, pp. 837-865.

Desmet, P.M.A. and Pohlmeyer, A.E. (2013), "Positive Design: An Introduction to Design for Subjective WellBeing”, International Journal of Design, Vol. 7 No. 3, pp. 5-19.

DIN (2008), Ergonomie - Körpermaße des Menschen - Teil 1: Begriffe, Messverfahren No. DIN 33402-1, Beuth, Berlin.

DIN (2017), Wesentliche Maße des menschlichen Körpers für die technische Gestaltung - Teil 1: Körpermaßdefinitionen und-messpunkte No. DIN EN ISO 7250-1, Beuth, Berlin.

Folstein, M.F., Folstein, S.E. and McHugh, P.R. (1975), "Mini-mental state". A practical method for grading the cognitive state of patients for the clinician", Journal of Psychiatric Research, Vol. 12 No. 3, pp. 189-198.

Frey, B. (1993), Zur Bewertung von Anmutungsqualitäten, Beiträge zum Produkt-Marketing, Vol. 22, Förderges, Produkt-Marketing, Köln.

Goldberg, L.R. (1990), “An Alternative "Description of Personality": The Big-Five Factor Structure”, Journal of Personality and Social Psychology, Vol. 59 No. 6, pp. 1216-1229.

Goodman, J., Langdon, P. and Clarkson, P.J. (2007), "Formats for User Data in Inclusive Design", In: C. Stephanidis, (Ed.), Universal access in human computer interaction, Lecture Notes in Computer Science, Vol. 4554, Springer, Berlin, pp. 117-126.

Götze, R., Zenz, K. and Michal, C. (2005), Neuropsychologisches Befundsystem für die Ergotherapie, 2nd ed., Springer, Heidelberg.

Güllich, A. and Krüger, M. (2013), Sport, Springer, Berlin, Heidelberg. 
Hotzman, J., Gordon, C.C., Bradtmiller, B., Corner, B.D., Mucher, M., Kristensen, S., Paquette, S. and Blackwell, C.L. (2011. Measurer's Handbook: US Army and Marine Corps Anthropometric Survey, Available at: http://www.dtic.mil/dtic/tr/fulltext/u2/a548497.pdf.

Kett, S.G. and Wartzack, S. (2016), Considering Emotional Impressions in Product Development: Quality of Life Theory and Its Impact on Design Strategy, 16.-19.05.2016, Dubrovnik, Croatia.

Kliegel, M. and Jäger, T. (2006), "Die Entwicklung des prospektiven Gedächtnisses über die Lebensspanne", Zeitschrift für Entwicklungspsychologie und Pädagogische Psychologie, Vol. 38 No. 4, pp. 162-174.

Kotler, P. and Armstrong, G. (2016), Principles of marketing, 16 ed., Pearson, Harlow.

Meinel, K. and Schnabel, G. (2018), Bewegungslehre - Sportmotorik: Abriss einer Theorie der sportlichen Motorik unter pädagogischem Aspekt, Meyer \& Meyer Verlag, Aachen.

Miehling, J., Schuhhardt, J., Paulus-Rohmer, F. and Wartzack, S. (2015), “Computer Aided Ergonomics Through Parametric Biomechanical Simulation”, ASME 2015 International Design Engineering Technical Conferences and Computers and Information in Engineering Conference, Boston, Massachusetts, USA, August 2-5, 2015, American Society of Mechanical Engineers, New York.

OECD (2013), OECD Guidelines on Measuring Subjective Well-being, OECD Publishing, Paris.

Osgood, C.E. (1957), The measurement of meaning, University of Illinois Press, Urbana.

Robins, R.W., Tracy, J.L. and Sherman, J.W. (2016), "What kinds of methods do personality psychologists use? A survey of Journal Editors and editorial board members", In: R.W. Robins, R.C. Fraley and R.F. Krueger, (Ed.), Handbook of research methods in personality psychology, Guilford, New York, London, pp. 673678.

Russell, J.A. (1980), “A Circumplex Model of Affect”, Journal of Personality and Social Psychology, Vol. 39 No. 6, pp. 1161-1178.

Schlick, C.M., Bruder, R. and Luczak, H. (2010), Arbeitswissenschaft, Springer Berlin Heidelberg, Berlin, Heidelberg.

Schmerling, D. (2013), The Measurement Of Motivation: Examining The Measurement Properties Of The Motivation Assessment System, Dissertation, Department of Industrial and Organizational Psychology, University of Central Florida, Orlando.

Schröppel, T., Miehling, J. and Wartzack, S. (2019), Roadmap für die Entwicklung einer Methodik zur dualen Nutzerintegration, Stuttgarter Symposium für Produktentwicklung. 16.05.2019, Stuttgart, accepted Paper.

Schröppel, T. and Wartzack, S. (2018), "Making a difference: Integrating physiological and psychological needs in user description”, In: P. Ekströmer, Simon Schütte and Johan Ölvander, (Ed.), Proceedings of NordDesign 2018, Linköping, Sweden, 14th - 17th August 2018, LiU Tryck, Linköping, pp. 1-10.

Wakula, J., Berg, K., Schaub, K., Bruder, R., Glitsch, U., Ellegast, R., and Institut für Arbeitswissenschaft der TU Darmstadt, BGIA and Unfallversicherung Sankt Augustin (2009), Der montagespezifische Kraftatlas, Technische Informationsbibliothek u. Universitätsbibliothek; BGIA, Hannover, Sankt Augustin.

Wall, M. and Sadun, A.A. (1989), New Methods of Sensory Visual Testing, Springer, New York.

Wentura, D. and Degner, J. (2006), "Indirekte Messung von Einstellungen mit kognitionspsychologischen Verfahren: Chancen und Probleme”, In: E.H. Witte, (Ed.), Evolutionäre Sozialpsychologie und automatische Prozesse: Beiträge des 21. Hamburger Symposions zur Methodologie der Sozialpsychologie, Pabst Science Publ, Lengerich.

Wickens, C.D., Lee, J.D., Liu, Y. and Gordon Becker, S.E. (2004), An introduction to human factors engineering, 2nd ed., Pearson Prentice Hall, Upper Saddle River, N.J.

Zöller, S.G. and Wartzack, S. (2017), “Considering Users' Emotions in Product Development Processes and the Need to Design for Attitudes”, In: S. Fukuda, (Ed.), Emotional Engineering, 5th ed., Springer, Cham, pp. 69-97.

\section{ACKNOWLEDGMENTS}

The authors gratefully acknowledge the financial support of project WA 2913/32-1 by the German Research Foundation (DFG). The authors are responsible for the content of this publication. 